\title{
Removal of iron and manganese from groundwater sources using nano-biosorbents
}

\author{
Mohammad Akbari Zadeh, Allahyar Daghbandan* (10) and Behrouz Abbasi Souraki
}

\begin{abstract}
Background: The presence of iron (Fe) and manganese $(\mathrm{Mn})$ ions in rocky beds leads to groundwater pollution. Moreover, their excessive concentration causes bad taste and color stains of water.

Methods: Tea leaves-derived char (TLC), rice straw-derived char (RSC), and nanosilica (NS) were used to adsorb Fe and $\mathrm{Mn}$ ions from water sources. The effects of parameters such as contact time, composition percentage, and particle size of biosorbents in a fixed-bed adsorption column were investigated.

Results: The study on the adsorption of Fe and Mn ions showed that the amount of adsorption increased significantly by decreasing the particle size. Furthermore, the combination of nano-biosorbents with nanosilica improved the adsorption. The Thomas and Adams-Bohart models adequately indicated the adsorption of Fe and Mn ions onto nano-biosorbents in the column mode. The TLC and RSC with NS are applicable for the removal of Fe and Mn ions from groundwater.

Conclusions: According to the BET analysis results, with more crushing of biosorbents by ball mill and placing them in the furnace, specific surface area of tea leaves and rice straw increased from 0.29 to 3.45 and from 3.70 to 10.99 $\mathrm{m}^{2} / \mathrm{g}$, respectively. The absorption of iron and manganese from the aqueous solution increased with the percentage of nano-silica. According to breakthrough curves, under best conditions (the seventh mode), nano-biosorbents could remove $98.05 \%$ and $97.92 \%$ of iron and manganese ions, respectively. The maximum equilibrium capacity of the adsorption column ( $\mathrm{mg} / \mathrm{g}$ ) was 256.56 for iron and 244.79 for manganese.
\end{abstract}

Keywords: Iron, Manganese, Tea leaves, Rice straw, Char, Nanosilica, Fixed bed column

*Correspondence: daghbandan@guilan.ac.ir

Department of Chemical Engineering, Faculty of Engineering, University

of Guilan, Rasht, Iran 


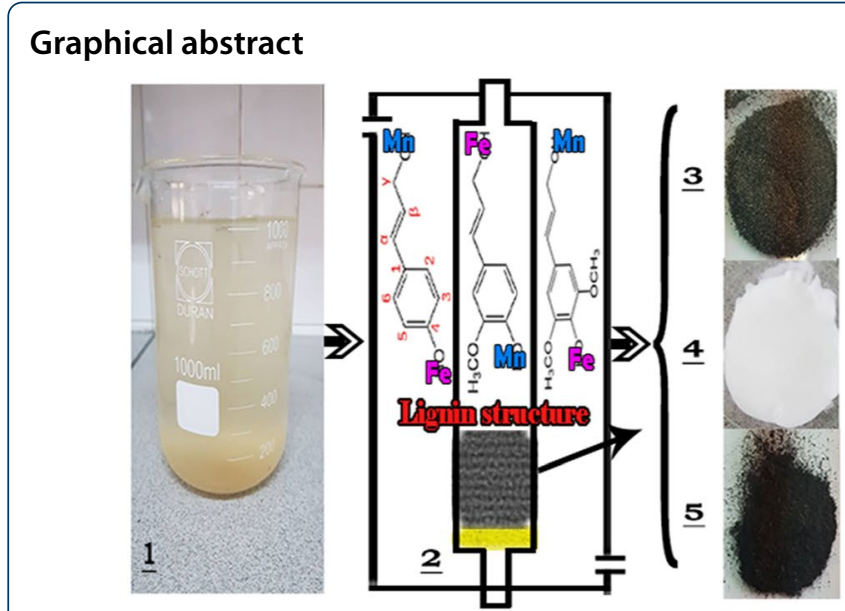

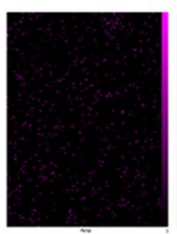
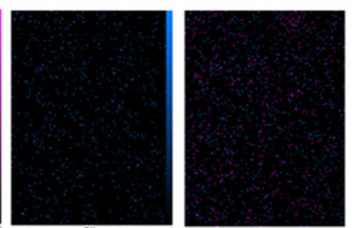

$\underline{6}$

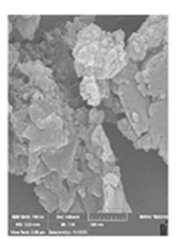

9

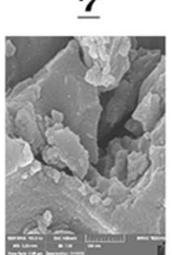

10

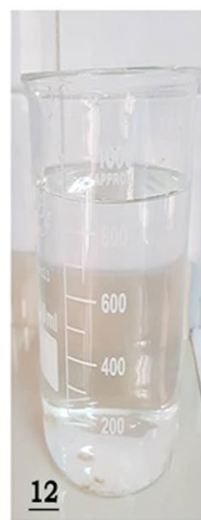

11

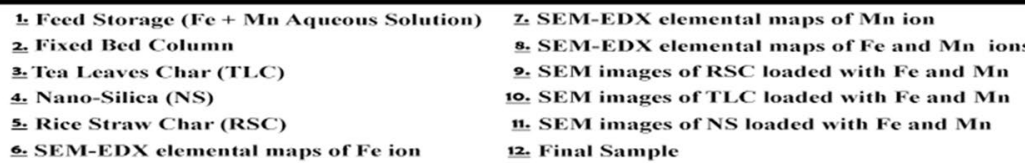

1. Feed Storage (Fe + Mn Aqueous Solution) z. SEM-EDX elemental maps of Mn ion

2. Fixed Bed Column

3. Tea Leaves Char (TLC)

4. Nano-Silica (NS)

5. Rice Straw Char (RSC)

6. SEM-EDX elemental maps of Fe ion

\section{Introduction}

Iron and Manganese are two metals commonly found in wells water [1]. This is also due to the presence of a rocky bed in the groundwater, causing excessive metal taste and stains [2]. The permissible level of $\mathrm{Mn}$ is $0.5 \mathrm{mg} / \mathrm{l}$. Drinking water standards set the maximum allowable amount of iron at $0.3 \mathrm{mg} / \mathrm{l}$, because higher levels are undesirable for industrial and domestic use [3]. Due to environmental and health issues, the removal of Fe and $\mathrm{Mn}$ ions from water resources by surface adsorption and a low-cost adsorbent has been discussed [4]. Among various methods available for removal of metallic elements, the adsorption process is preferred owing to its flexibility, high efficiency, reproducibility and being economical [5]. Natural or modified biomaterials, by-products, or waste from industrial and agricultural operations are the most important sources of low cost adsorbents [6,7]. Most studies on the removal of metal ions in surface and groundwater are performed using a batch system, which is generally and easily applicable in laboratory studies and limited to the processing of water sources in small quantities [8-10]. The removal of methylene blue from water by tea waste active with $\mathrm{H}_{3} \mathrm{PO}_{4}(\mathrm{H}-\mathrm{AC}), \mathrm{KOH}(\mathrm{K}-\mathrm{AC})$ and $\mathrm{ZnCl}_{2}(\mathrm{Z}-\mathrm{AC})$ agents has been studied by Toli et al. EDX, FTIR, FESEM, XRD and TGA analyses were performed on the adsorbents; the results showed that the adsorption capacity of $\mathrm{H}$-AC adsorbent for removal of methylene blue is higher than the others [11]. Hameed and El-Khaiary used RSC to remove malachite green. As for their results, RSC is suitable for removing dye from aqueous solutions [12]. Tai Han Nogoyan et al. studied the application of rice straw sorbent for removal of arsenic from water sources. FTIR and SEMEDX analyses were performed on the adsorbent. As such, by processing and converting ordinary adsorbent into RSC, the adsorption rate increased [13]. Moreover, the removal of cadmium from water using RSC was investigated by Zheng et al. RSC can be effective in removing cadmium from water [14]. The removal of methylene blue from water by Modified nano- $\mathrm{SiO}_{2}$ by Bismuth and Iron has been studied by Salimi et al. SEM, FTIR, XRD and TEM analyses were performed on the adsorbents; the XRD results showed that Nanosilica structure is amorphous [15]. In a batch system, the equilibrium time is short, and in a continuous system, the adsorbent is always in the vicinity of the fresh solution $[16,17]$. The use of multi wall carbon nanotubes (MWCNTs) for Cr(VI) removal from groundwater was investigated by Mpouras et al. Batch and column experiments were conducted to examine the effect of MWCNTs, initial concentration, $\mathrm{pH}$, contact time and breakthrough curves. The results showed that $\mathrm{pH}$ is an effective parameter in removing $\mathrm{Cr}(\mathrm{VI})$ ion from groundwater [18]. The continuous system is inexpensive, cost effective and adaptable to the ongoing process $[4,19]$. Himanshu Patel conducted a comprehensive study on the continuous fixed bed adsorption process in 2019, studying more than 100 titles of articles [5]. The use of tea waste for $\mathrm{Cu}$ and $\mathrm{Pb}$ removal 
from wastewater was investigated by Emersing et al. The experiments were performed in a fixed bed column; the effect of adsorbent dose, initial concentration, $\mathrm{pH}$, particle size and breakthrough curves was assessed. As for the results, tea waste was effective in removing $\mathrm{Cu}$ and $\mathrm{Pb}$ ions from wastewater [20]. Peng $\mathrm{Fu}$ et al. examined the impact of pyrolysis temperature and heating rate on the production of activated carbon from rice straw; with increasing pyrolysis temperature and decreasing heating rate, the specific surface area of the adsorbent increased [21]. Vilardi et al. studied the removal of nitrate green by batch and fixed-bed columns packed method with waste biomass. The outcome was that the acidic environment was favorable for the removal of nitrate [22]. A wide variety of lignocellulosic biomasses have been investigated as biosorbents for the removal of metal ions from aqueous environments. Rice straw and tea leaves or their derivatives are two major lignocellulosic-based biosorbents, mainly composed of cellulose, hemicellulose and lignin. These compounds participate in metal ion bonding through such multiple functional groups as hydroxyl, carboxyl, carbonyl, and amine on the cell wall [23, 24]. Many studies has been conducted on the removal of metal ions from drinking water sources using rice straw-derived char, tea leavesderived char and nanosilica; the superiority of modified adsorbents in the removal of disturbing ions in water has been proved [13, 15, 25-30]. Various analyses such as X-ray diffractometer (XRD) [15, 31, 32], Fourier transforms infrared spectra (FTIR) [24, 33], scanning electron microscopy (SEM), the energy dispersive X-ray (EDX) [13-15] and Brunauer-Emmett-Teller (BET) $[34,35]$ were used to determine different indicators of adsorbents. In the present study, removal of Fe and Mn from aqueous solution was performed with low-cost adsorbent. The experiments were performed in a fixed bed column. The mathematical methods of Thomas and Adams-Bohart were used to describe the breakthrough curves. The biosorbents was also tested through real samples taken from Groundwater sources of drinking water located in Shaft City in Gilan province, North of Iran. The results indicate that the proposed biosorbents are a suitable alternative for removing metal ions from water sources.

\section{Materials and methods}

\section{Preparation of metal solutions}

For preparation of synthetic water solutions, analytical grades of Iron (III) chloride (with a chemical formula $\mathrm{FeCl}_{3} \cdot 6 \mathrm{H}_{2} \mathrm{O}$ ) and Manganese (II) sulfate (with a chemical formula $\mathrm{MnSO}_{4} \cdot \mathrm{H}_{2} \mathrm{O}$ ) were dissolved in tap water to give a concentration of $1000 \mathrm{mg} / \mathrm{l}$ and diluting when necessary.

\section{Preparation of nano-biosorbants and nanosilica}

The raw tea leaves (TL) and rice straw (RS) were used as biosorbents. Samples were collected from tea plants and rice paddies in the North of Iran. At first, samples were several times washed with tap water for removal of such all traces as oil and dirt. The material was dried at room temperature for 3 days; for more drying, raw adsorbents were placed into oven with a temperature of $70{ }^{\circ} \mathrm{C}$ until its weight became constant. The Planetary ball mill was used to reduce adsorbent particles sizes. The adsorbents were placed in a ball mill at $600 \mathrm{rpm}$ for $20 \mathrm{~min}$. then; they were placed in a furnace at $400{ }^{\circ} \mathrm{C}$ for $3 \mathrm{~h}$. After $24 \mathrm{~h}$ passed, the biosorbents char were taken out of the furnace and stored in closed containers. Biosorbents char include tea leaves-derived char (TLC) and rice strawderived char (RSC). Silicon oxide nano powder (nanosilica) with chemical formula $\mathrm{SiO}_{2}$, amorphous structure, and hydrophilic type were purchased from Fine-Nano Company (Made By US-NANO) with $99.5 \%$ purity.

\section{Fixed bed column studies}

The adsorption process was carried out using Fe and Mn solution with a concentration of $5 \mathrm{mg} / \mathrm{l}$ as an artificial sample as well as $0.1 \mathrm{~g}$ of nano-biosorbents. A feed water reservoir (with $20 \mathrm{~L}$ capacity) was chosen with a heat source inside, its temperature controlled by a thermo regulator. Moreover, the inlet stream was placed over the reservoir; the feed flow was pumped by a variable flow pump (WS123) at a flow rate of $10 \mathrm{ml} / \mathrm{min}$. For the next step, the stream was conducted by a three-way pipe. One stream returned to the feed water reservoir and the other entered the flow meter. Subsequently, the stream entered the top of the column. The process was conducted in a continuous adsorption process with a fixed bed column (diameter of $1 \mathrm{~cm}$ and a height of $50 \mathrm{~cm}$ ). The absorption column had an outer protective body, covered by a heating element. At the column outlet, collection of the samples was done at different times for each test. The time intervals for the process ranged from 1, 2, 5, 10, 20 to 900 (min) minutes, respectively. The process temperature was $30{ }^{\circ} \mathrm{C}$. In addition, the $\mathrm{pH}$ value was 7.9. The flow was stopped once the column was fully marked by $\mathrm{C}_{\mathrm{t}}=\mathrm{C}_{0}$. For each test, samples were collected at a volume of $15 \mathrm{ml}$ for analysis using atomic adsorption (Agilent 240-280 Series AA) as effluent Fe and $\mathrm{Mn}$ ions concentration $\left(\mathrm{C}_{\mathrm{t}}\right)$. The column was washed with distilled water after each test. The schematic diagram of the fixed-bed column is presented in Fig. 1. 


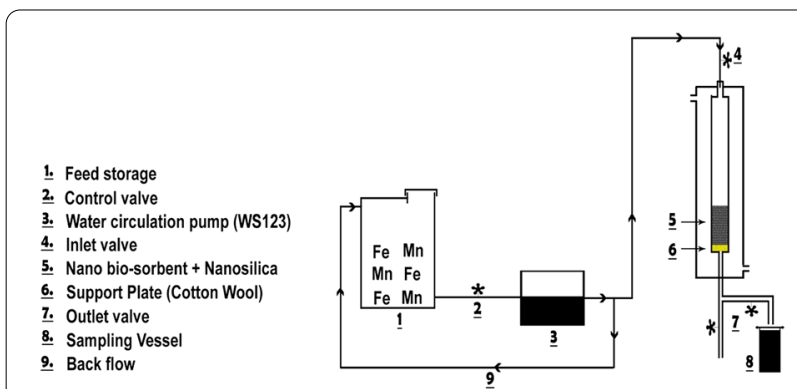

Fig. 1 Schematic diagram of the lab-scale column

The breakthrough curve is usually described as the ratio of the ions concentration at the outlet to the column inlet ratio $\left(C_{t} / C_{0}\right)$ in the function of time for the fixedbed column. The amount of adsorbed Fe and Mn was calculated by Eq. (1):

$$
q_{\text {total }}=\frac{Q * A}{1000}=\frac{Q}{1000} \int_{0}^{\mathrm{t}_{\text {total }}} \mathrm{C}_{\mathrm{ad}} \mathrm{dt}=\frac{Q}{1000} \int_{0}^{\mathrm{t}_{\text {total }}}\left(\mathrm{C}_{0}-\mathrm{C}_{\mathrm{t}}\right) \mathrm{dt}
$$

where ${ }_{\text {qtotal }}$ indicates the maximum removal capacity of column in $\mathrm{mg}, Q$ is the volumetric flow rate circulating through the column in $\mathrm{ml} / \mathrm{min}, A$ is the area under the breakthrough curve in $\mathrm{m}^{2}, t_{\text {total }}$ is the total flow time in $\mathrm{min}, \mathrm{C}_{\mathrm{ad}}$ is the absorbed removal concentration in $\mathrm{mg} / \mathrm{l}$. $\mathrm{C}_{0}$ and $\mathrm{C}_{\mathrm{t}}$ are the $\mathrm{Fe}$ and $\mathrm{Mn}$ ions concentrations $(\mathrm{mg} / \mathrm{l})$ in inlet and outlet flows, respectively. The equilibrium capacity of the column ( $\mathrm{mg} / \mathrm{g})$ was obtained by Eq. (2), where $m$ is the dry absorbent mass $(g)$ :

$$
q_{\mathrm{eq}}=\frac{q_{\mathrm{total}}}{m}
$$

$m_{\text {total }}$ is the total mass absorbed into the column in $\mathrm{mg}$, which is obtained using Eq. (3):

$$
m_{\text {total }}=\frac{C_{0} Q t_{\text {total }}}{1000}
$$

$\% R$ is the total removal percentages of iron and manganese, which is obtained using Eq. (4):

$$
\% R=\frac{q_{\text {total }}}{m_{\text {total }}} \times 100
$$

In other words, $(\% R)$ is the ratio of the total removed ions in the column to the total amount of ions delivered to the column.

\section{Mathematical description}

Various simple mathematical models have been developed to describe and possibly predict the dynamic behavior of the bed in column performance. The most famous and widely applied models used in column performance theory are Thomas and Adams-Bohart [36].

\section{Thomas model}

Thomas model is one of the most common and widely used methods in expressing the theory of absorption column performance. It can predict the theoretical Breakthrough curve based on laboratory data (time and Output to input concentration ratio). The linearized form of the Thomas model can be expressed as follows:

Equation (5)

$$
\ln \left(\frac{\mathrm{C}_{0}-\mathrm{C}_{t}}{\mathrm{C}_{t}}\right)=\ln \left[\exp \left(\frac{K_{\mathrm{Th}} q_{0} M}{Q}\right)-1\right]-K_{\mathrm{Th}} \mathrm{C}_{0} t
$$

Here, $K_{\mathrm{Th}}(\mathrm{ml} / \mathrm{mg} \mathrm{min})$ is the Thomas rate constant; $q_{0}$ $(\mathrm{mg} / \mathrm{g})$ is the equilibrium uptake of metal ions. $M$ as the amount of adsorbent packed inside the column is denoted by $(\mathrm{mg}) . \mathrm{C}_{0}(\mathrm{mg} / \mathrm{l})$ is the influent concentration, $\mathrm{C}_{\mathrm{t}}(\mathrm{mg} / \mathrm{l})$ is the outlet concentration at each time; and $Q$ $(\mathrm{ml} / \mathrm{min})$ is the flow rate. Because the amount $\exp \left(\frac{K_{T h} q_{0} M}{Q}\right)$ is much larger than one, the equation is written as follows:

$$
\ln \left(\frac{\mathrm{C}_{0}-\mathrm{C}_{\mathrm{t}}}{\mathrm{C}_{\mathrm{t}}}\right)=\left(\frac{K_{\mathrm{Th}} q_{0} M}{Q}\right)-K_{\mathrm{Th}} \mathrm{C}_{0} t
$$

where $q_{0}$ and $K_{\mathrm{Th}}$ amounts could be obtained through the slope and width of the origin of the linear graphs, respectively, obtained by $\ln \left(\frac{\mathrm{C}_{0}-\mathrm{C}_{\mathrm{t}}}{\mathrm{C}_{\mathrm{t}}}\right)$ in terms of $t$ [37].

\section{Adams-Bohart model}

Adams-Bohart provides a simple basic model for describing the initial region of absorption, often adapting to failure curves with very high accuracy. It has aided researchers to determine important and key parameters, such as adsorption rate constants and adsorption capacity. The mathematical equation of the model can be written as Eq. (7):

$$
\ln \left(\frac{\mathrm{C}_{0}}{\mathrm{C}_{t}}-1\right)=\ln \left[\exp \left(\frac{K_{B A} N_{0} H}{U_{0}}\right)-1\right]-K_{B A} \mathrm{C}_{0} t
$$

As the amount $\exp \left(\frac{K_{B A} N_{0} H}{U_{0}}\right)$ is much larger than one, the equation is written as follows:

$$
\ln \left(\frac{C_{0}}{C_{t}}-1\right)=\frac{K_{B A} N_{0} H}{U_{0}}-K_{B A} C_{0} t
$$

Here, $C_{0}(\mathrm{mg} / \mathrm{l})$ is the inlet concentrations. $C_{t}(\mathrm{mg} / \mathrm{l})$ is the outlet concentration at each time. $H(\mathrm{~cm})$ is the bed height and $U_{0}(\mathrm{~cm} / \mathrm{min})$ is the superficial velocity, which is obtained through dividing the flow rate by the cross 
section of the column. $K_{\mathrm{BA}}(1 / \mathrm{mg} \mathrm{min})$ is the Kinetic coefficient or constant Adams-Bohart absorption rate; and $N_{0}$ is volumetric absorption capacity $(\mathrm{mg} / \mathrm{l}) . N_{0}$ and $K_{\mathrm{BA}}$ amounts could be obtained by the slope and width of the origin of the linear graphs, respectively; they are obtained practically by $\ln \left(\frac{\mathbf{C}_{0}}{\mathbf{C}_{t}}-1\right)$ in terms of $t$ [38].

\section{Results}

\section{Investigating the structure of biosorbents using XRD}

The X-ray powder diffraction (XRD) is an acceptable technique in the study of crystal properties.

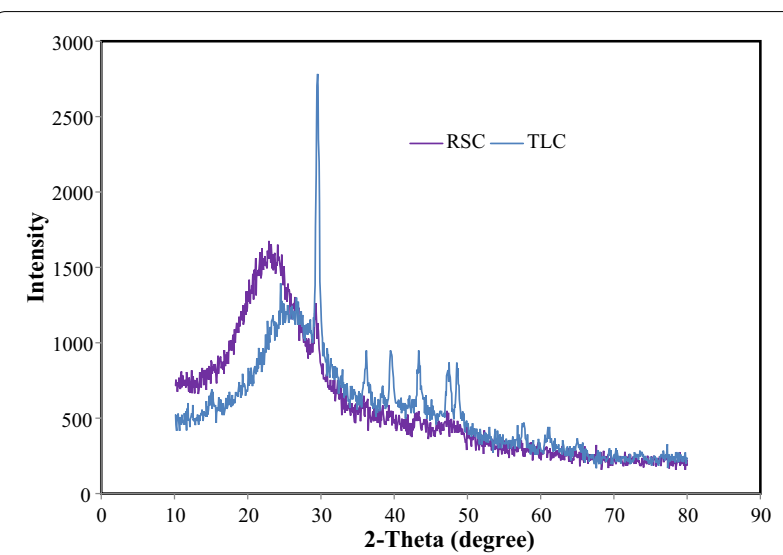

Fig. 2 X-ray powder diffraction (XRD) for TLC and RSC
This analysis was used to investigate the phases and structure of TLC and RSC. The results of the XRD test are presented in Fig. 2.

The information presented in Fig. 2 is associated with the TLC and RSC. The RSC chart shows a peak at $22.9^{\circ}$ with several other small peaks in the rest of the range. The TLC chart displays a peak at $24.5^{\circ}$, a larger peak at $29.55^{\circ}$ and several other peaks in other ranges.

\section{SEM combined with EDX spectrum analyses}

The surface morphology of loaded samples with Fe and Mn are displayed in Figs. 3, 4 and 5. The samples treated with Fe and Mn had a rougher surface; they were covered with small flocculent material which resembled fibers. This phenomenon is likely due to an inorganic layer formed on the surface of adsorbents by $\mathrm{Mn}$ and Fe ions. EDX analysis was used to prove the effective loading of iron and manganese on biosorbents.

As shown in Figs. 3, 4 and 5, the main elements existing in the TLC, RSC and NS were Fe and Mn. Such findings suggest that biosorbents could adsorb $\mathrm{Fe}$ and $\mathrm{Mn}$ ions from the aqueous solution. This also assumes that the adsorption process of $\mathrm{Fe}$ and $\mathrm{Mn}$ ions onto biosorbents may be physical in nature. In general, rough surfaces and extensively distributed pores can suggest a larger surface area and more attached metal sites.

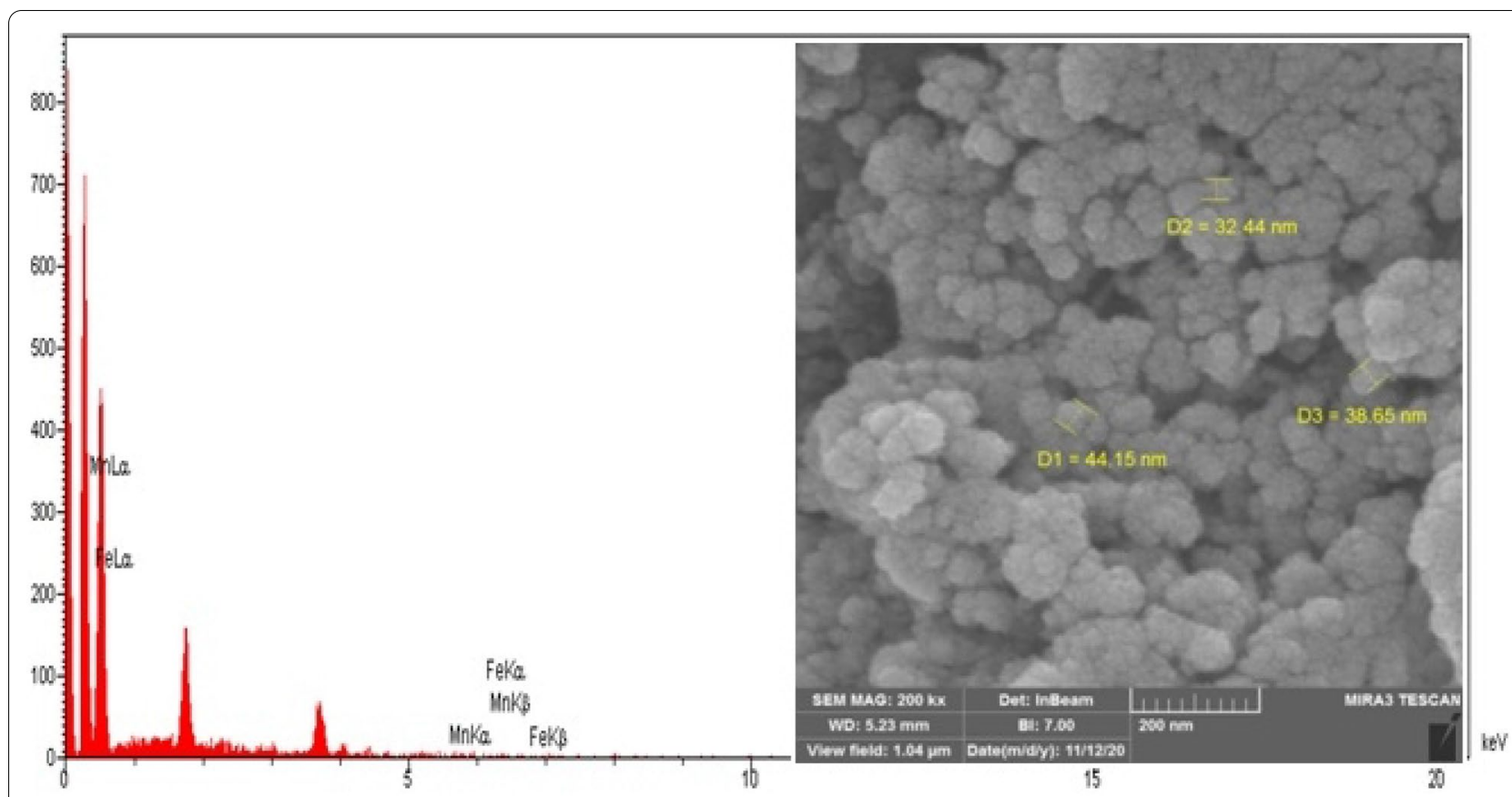

Fig. 3 EDX spectrum and SEM images of RSC loaded with Fe and Mn 


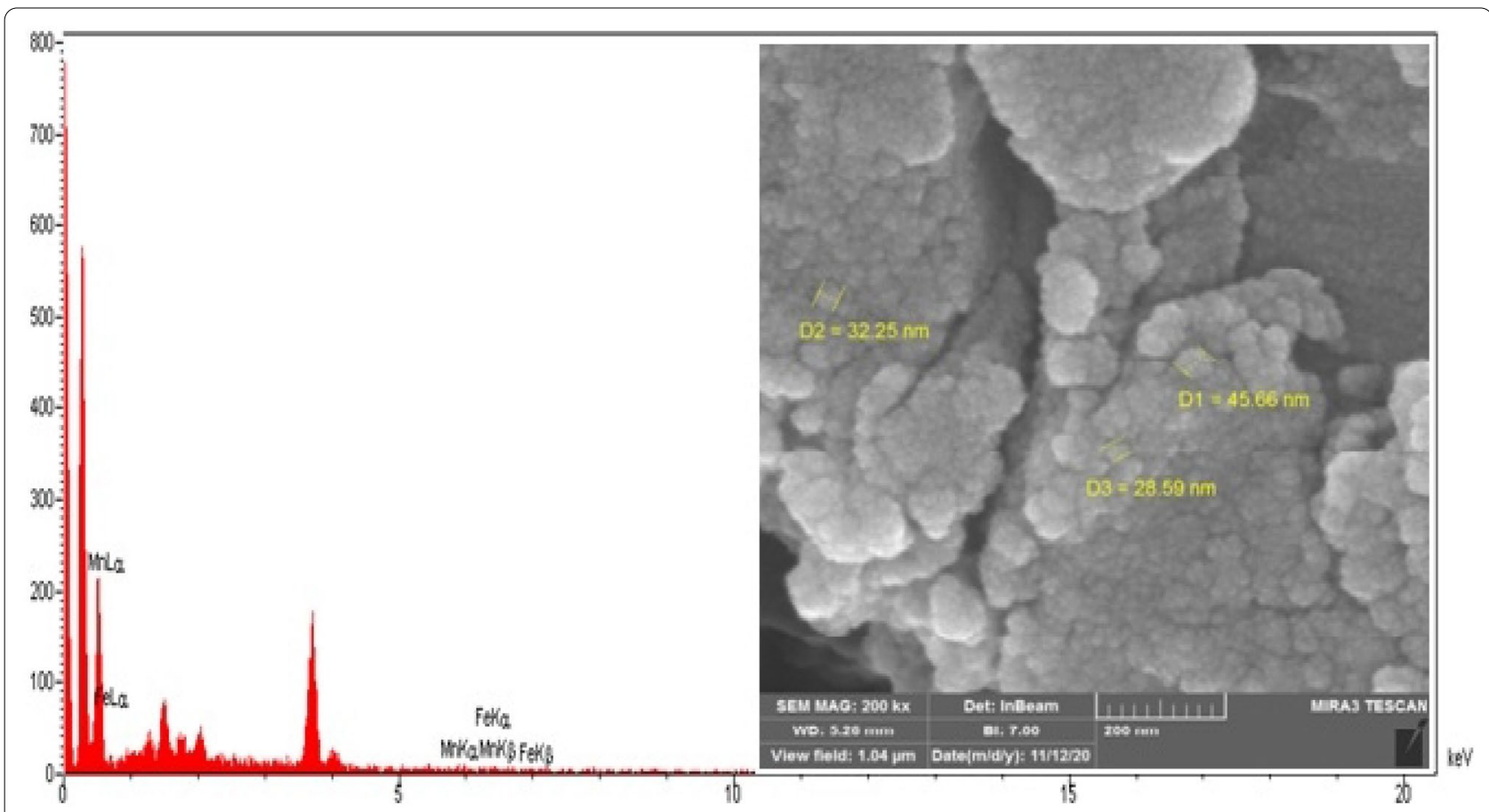

Fig. 4 EDX spectrum and SEM images of TLC loaded with Fe and Mn

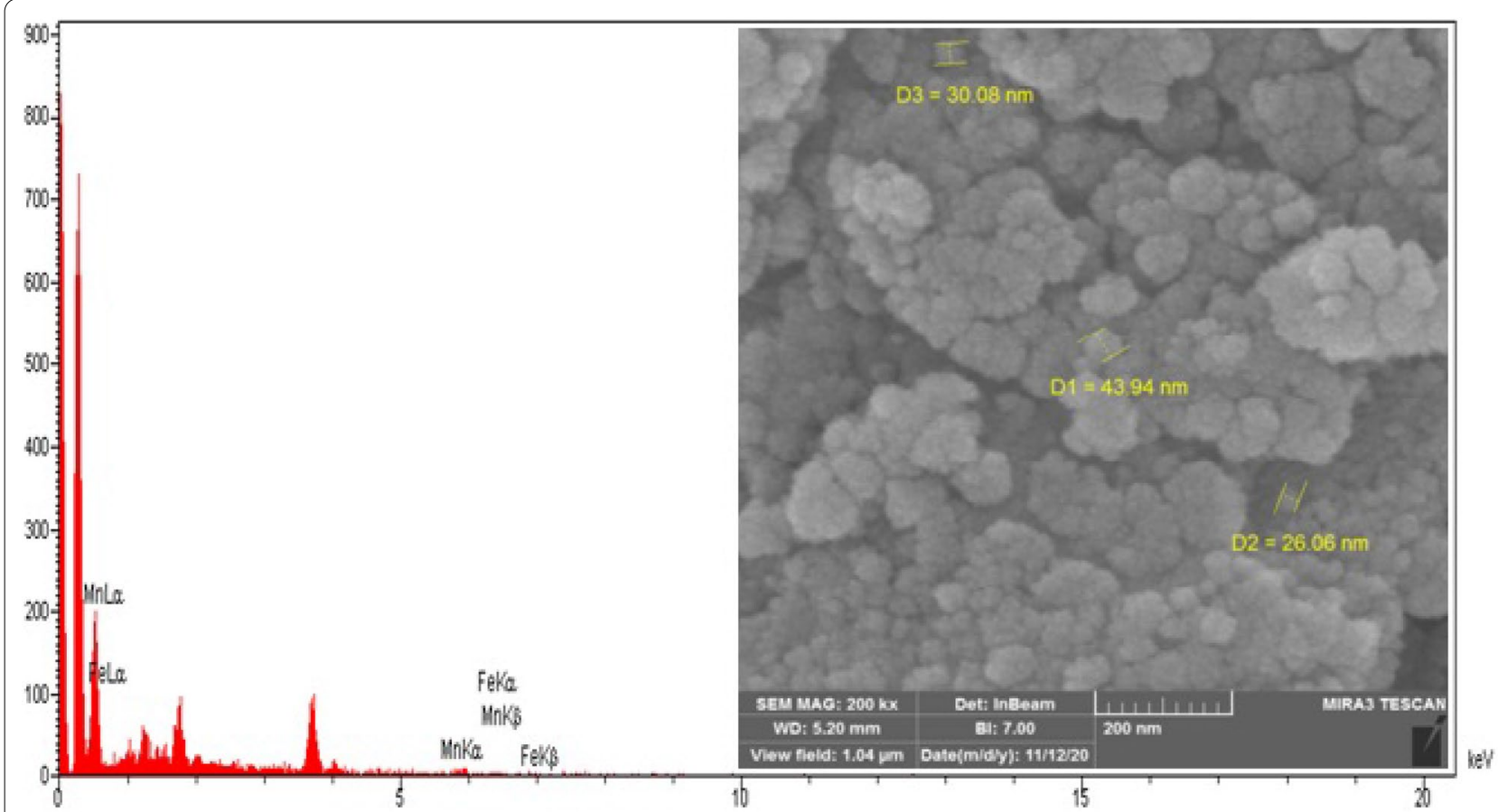

Fig. 5 EDX spectrum and SEM images of NS loaded with Fe and Mn 
Table 1 Surface area, volume and Pore size of biosorbents

\begin{tabular}{|c|c|c|c|c|c|c|c|}
\hline \multirow[t]{2}{*}{ Parameter } & \multicolumn{5}{|c|}{ Surface area } & \multirow{2}{*}{$\begin{array}{l}\text { Total pore } \\
\text { volume }\left(\mathrm{m}^{3} / \mathrm{g}\right)\end{array}$} & \multirow[t]{2}{*}{ Pore size $(\mathrm{nm})$} \\
\hline & Sample & $\mathrm{BET}\left(\mathrm{m}^{2} / \mathrm{g}\right)$ & Langmuir $\left(\mathrm{m}^{2} / \mathrm{g}\right)$ & t-Plot $\left(\mathrm{m}^{2} / \mathrm{g}\right)$ & BJH plot $\left(\mathrm{m}^{2} / \mathrm{g}\right)$ & & \\
\hline \multirow[t]{4}{*}{ Value } & $\mathrm{TL}$ & 0.29 & 0.3964 & 0.237 & 1.5176 & 0.0037707 & 52.25 \\
\hline & TLC & 3.45 & 4.0278 & 3.3516 & 3.4323 & 0.039601 & 45.888 \\
\hline & RS & 3.70 & 3.0634 & 1.3938 & 6.3386 & 0.01735 & 18.731 \\
\hline & RSC & 10.99 & 12.959 & 10.71 & 9.399 & 0.060231 & 21.922 \\
\hline
\end{tabular}

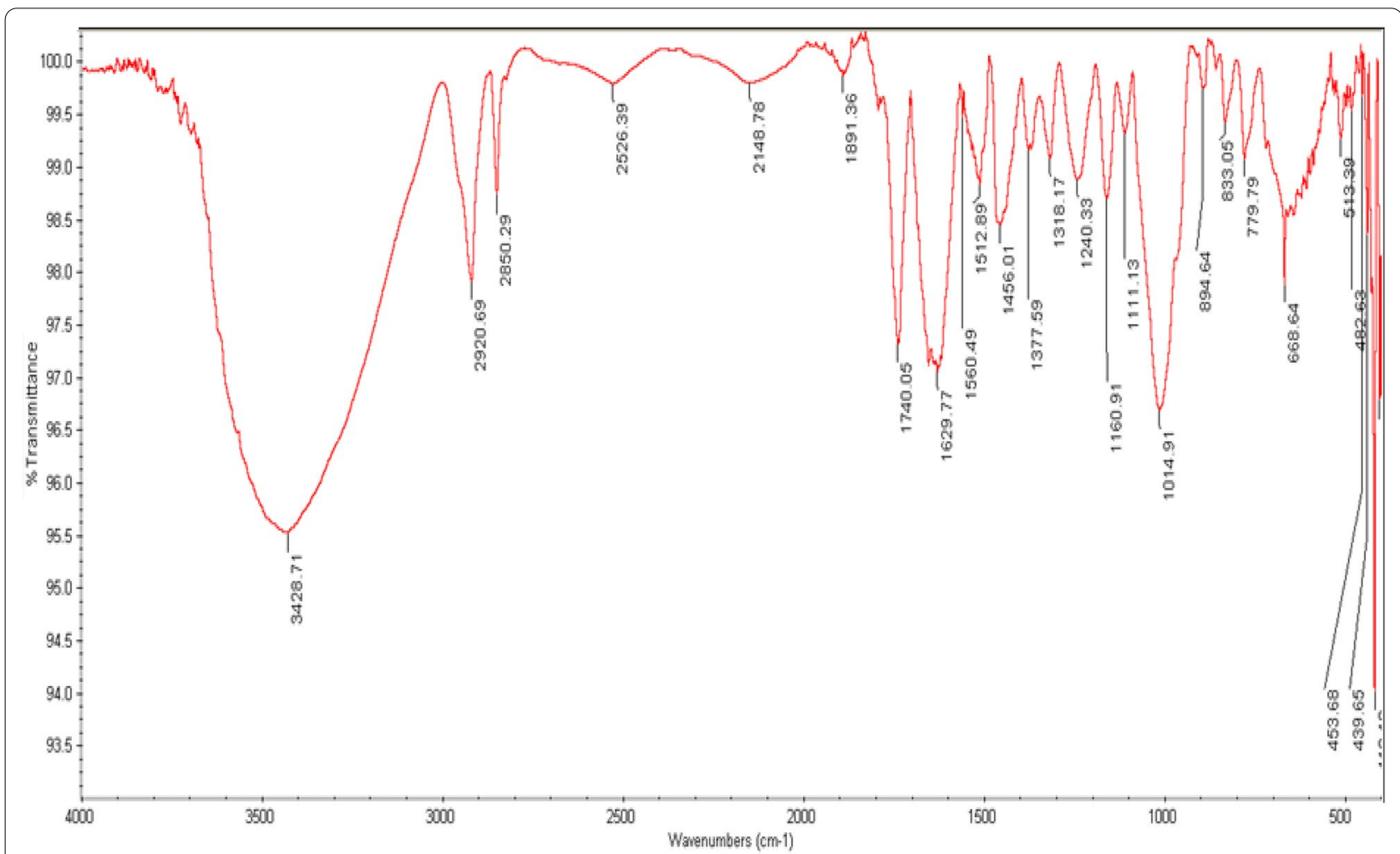

Fig. 6 FT-IR spectral characteristics of Tea Leaves

\section{Surface area and pore diameter (BET and BJH analyses)}

BET analysis is used to study the surface of materials and their porosity. Adsorptive characterization by $\mathrm{N}_{2}$ is one of the most widely used techniques to assess textural properties of porous solids. $\mathrm{BJH}$ analysis can also be employed to determine pore area and specific pore volume using adsorption and desorption techniques. The Physical characteristics of biosorbents are presented in Table 1.

\section{Fourier transforms infrared spectra (FTIR)}

The functional groups of biosorbents are analyzed using FTIR. Figures 6 and 7 show the FT-IR spectra of tea leaves and rice straw. According to Fig. 6, the peak created in $3428.71 \mathrm{~cm}^{-1}$ corresponds to the hydroxyl $-\mathrm{OH}$ group. In $2920.69 \mathrm{~cm}^{-1}$, it can be observed that the presence of alpha $-\mathrm{CH}$ groups; and the peak $2850.29 \mathrm{~cm}^{-1}$ indicates the presence of alcohol groups. The peaks of 1740.05 and $1629.77 \mathrm{~cm}^{-1}$ demonstrate the presence of anhydride groups $\mathrm{C}=\mathrm{O}$. Those of $1560.49 \mathrm{~cm}^{-1}$ and $1512.89 \mathrm{~cm}^{-1}$ imply the presence of aromatic compounds $\mathrm{C}=\mathrm{C}$. The other peaks in the range 1400 to $1000 \mathrm{~cm}^{-1}$ are related to Stretching Vibration $\mathrm{C}-\mathrm{O}$ and Bending Vibration $-\mathrm{OH}$ in the ether, ester and carboxylic acid groups. As observed through the analysis of tea leaves, these biosorbents have a variety of carbonaceous compounds. According to Fig. 7, the peak created in $3424.12 \mathrm{~cm}^{-1}$ belongs to the hydroxyl group $-\mathrm{OH}$ and intracellular waters. In $2920.28 \mathrm{~cm}^{-1}$, we see the presence 


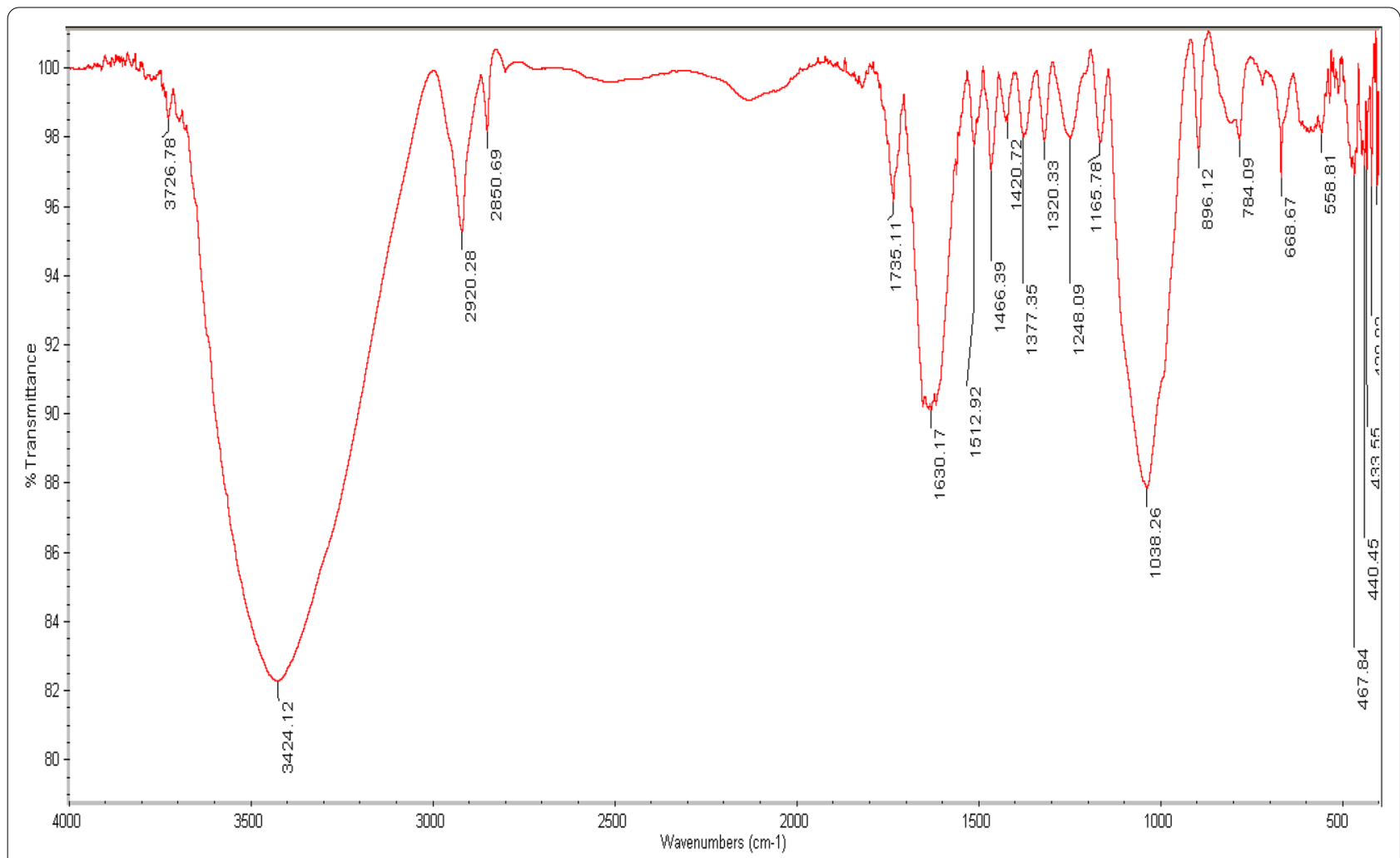

Fig. 7 FT-IR spectral characteristics of Rice Straw

of alpha-acid - $\mathrm{CH}$ groups; and the peak $2850.69 \mathrm{~cm}^{-1}$ represents the presence of alcoholic groups $-\mathrm{OH}$; the peak $2130 \mathrm{~cm}^{-1}$ shows the presence of alkyne groups $\mathrm{C} \equiv \mathrm{C}$. In addition, the peak created in $1735.11 \mathrm{~cm}^{-1}$ signifies the presence of $\mathrm{C}=\mathrm{O}$ groups of carbonyl, ester and carboxylic acids. In addition, peaks $1630.17 \mathrm{~cm}^{-1}$ can indicate the presence of alkene and aromatic compounds $\mathrm{C}=\mathrm{C}$ or compounds with $\mathrm{C}=\mathrm{N}$. Other peaks in the range of 1400 to $1000 \mathrm{~cm}^{-1}$ are related to Stretching Vibration $\mathrm{C}-\mathrm{O}$ and Bending Vibration $-\mathrm{OH}$ in the groups of ether, ester and carboxylic acids groups. Moreover, the peak $1038.26 \mathrm{~cm}^{-1}$ can imply the presence of amino compounds $\mathrm{C}-\mathrm{N}$. Rice straw has a variety of carbonaceous compounds as well. This variety contributes to a better understanding of the functional groups that play a key role in the absorption process.

\section{Analysis of experimental data}

The effect of modified adsorbents and those combinations with NS in the process of fixed bed continuous adsorption were investigated. To examine the effect of adsorption percentage and particle size of adsorbents on adsorption capacity, 7 different combinations of TLC, RSC and NS adsorbents were studied. The percentages of $\mathrm{Fe}$ and $\mathrm{Mn}$ ions removal at different times by different combinations of adsorbents are shown in Table 2. By plotting the ratio of ions concentration at the output to the input column $\left(C_{t} / C_{0}\right)$ in terms of time, Breakthrough curves were obtained. When the ratio of the final concentration $\left(C_{t}\right)$ to the initial concentration $\left(C_{0}\right)$ is equal to 0.1 , it is denoted by $t_{1}$, and when this ratio is equal to 0.9 , it is denoted by $t_{2}$.

\section{Breakthrough studies}

The results of Table 2 are illustrated in Figs. 8 and 9. Regarding the adsorbents, during the first $60 \mathrm{~min}$ of contact, the amount of Fe and $\mathrm{Mn}$ in solution decreased sharply. Over time, a gradual decrease in adsorption kinetics occurred. When the approximate time of 900 min was reached, the process was stopped and the final concentration was almost equal to the initial one.

To study the effect of adsorbent compound type and percentage in the fixed bed continuous adsorption process, 7 different nano-biosorbents compounds were prepared and tested. The percentage of metal adsorption rises as NS increase. The results show that the adsorbent performance of NS with RSC works more efficiently TLC; this is due to higher specific surface area of RSC. 
Table 2 Equilibrium capacity and percentage of Fe and Mn removal in a fixed bed column using different combinations of adsorbents

\begin{tabular}{|c|c|c|c|c|c|c|}
\hline No. & Adsorbent & Absorbed & $t_{1}(\min )$ & $t_{2}(\min )$ & $q_{\mathrm{eq}}(\mathrm{mg} / \mathrm{g})$ & $\% R$ \\
\hline \multirow[t]{2}{*}{1} & $\operatorname{RSC}(0.1 \mathrm{~g})$ & $\mathrm{Fe}$ & 2 & 720 & 225.92 & 88.59 \\
\hline & & $\mathrm{Mn}$ & 2 & 660 & 215.03 & 86.01 \\
\hline \multirow[t]{2}{*}{2} & $\mathrm{TLC}(0.1 \mathrm{~g})$ & $\mathrm{Fe}$ & 1 & 540 & 130.03 & 72.24 \\
\hline & & $\mathrm{Mn}$ & 1 & 420 & 110.38 & 52.56 \\
\hline \multirow[t]{2}{*}{3} & RSC $(0.05 \mathrm{~g})+\mathrm{NS}(0.05 \mathrm{~g})$ & $\mathrm{Fe}$ & 20 & 800 & 245.29 & 95.14 \\
\hline & & $\mathrm{Mn}$ & 10 & 750 & 236.30 & 94.52 \\
\hline \multirow[t]{2}{*}{4} & $\mathrm{TLC}(0.05 \mathrm{~g})+\mathrm{NS}(0.05 \mathrm{~g})$ & $\mathrm{Fe}$ & 1 & 600 & 156.41 & 75.19 \\
\hline & & $\mathrm{Mn}$ & 1 & 540 & 141.23 & 67.25 \\
\hline \multirow[t]{2}{*}{5} & RSC $(0.04 \mathrm{~g})+\mathrm{TLC}(0.04 \mathrm{~g})+\mathrm{NS}(0.02 \mathrm{~g})$ & $\mathrm{Fe}$ & 1 & 660 & 191.03 & 81.64 \\
\hline & & $\mathrm{Mn}$ & 2 & 600 & 195.19 & 78.08 \\
\hline \multirow[t]{2}{*}{6} & $\operatorname{RSC}(0.025 \mathrm{~g})+\mathrm{TLC}(0.025 \mathrm{~g})+\mathrm{NS}(0.05 \mathrm{~g})$ & $\mathrm{Fe}$ & 10 & 750 & 237.37 & 91.74 \\
\hline & & $\mathrm{Mn}$ & 5 & 720 & 226.68 & 90.67 \\
\hline \multirow[t]{2}{*}{7} & $\operatorname{RSC}(0.015 \mathrm{~g})+\mathrm{TLC}(0.015 \mathrm{~g})+\mathrm{NS}(0.07 \mathrm{~g})$ & $\mathrm{Fe}$ & 40 & 900 & 256.56 & 98.05 \\
\hline & & $\mathrm{Mn}$ & 20 & 900 & 244.79 & 97.92 \\
\hline
\end{tabular}

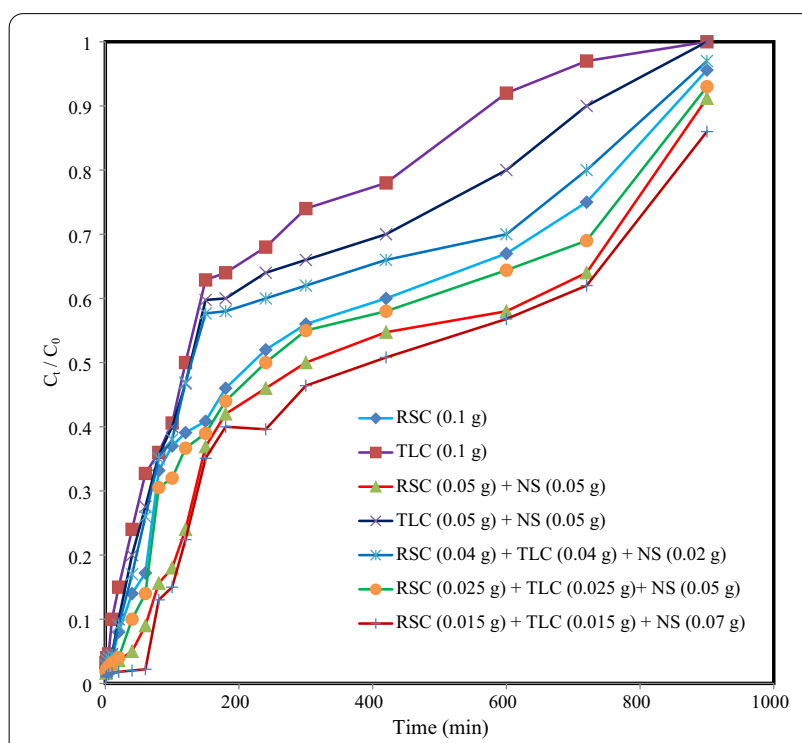

Fig. 8 Effect of time on iron adsorption with different combinations of biosorbents (Breakthrough curves)

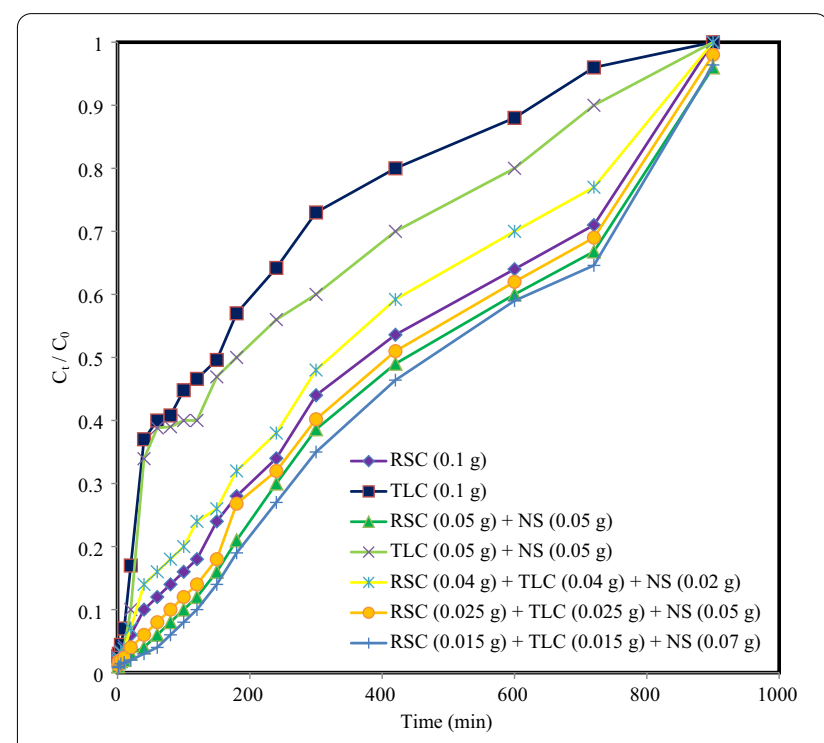

Fig. 9 Effect of time on manganese adsorption with different combinations of biosorbents (Breakthrough curves)

Industrial application of biosorbents

To find out whether the proposed method can be used for drinking water resources, ten control samples (Table 4) were collected from groundwater in Shaft city, Guilan Province in the North of Iran. Temperature, $\mathrm{pH}$, turbidity and color parameters of the collected water samples were measured before treatment. In the proposed method, the adsorbent dose was $0.1 \mathrm{~g}$; the maximum contact time was $720 \mathrm{~min}$; and temperature was $30{ }^{\circ} \mathrm{C}$. The concentration of iron and manganese ions was measured by an atomic absorption spectrophotometer (Agilent 240_280 Series 
Table 3 Parameters of Thomas and Adams-Bohart model for iron and manganese adsorbtion by combination of TLC, RSC and NS

\begin{tabular}{|c|c|c|c|c|c|c|}
\hline Model & $\begin{array}{l}\text { Sample } \\
\text { number }\end{array}$ & Adsorbent & Absorbed & $K_{\mathrm{Th}}(\mathrm{ml} / \mathrm{mg} \mathrm{min})$ & $q_{0}(m g / g)$ & $R^{2}$ \\
\hline \multirow[t]{14}{*}{ Thomas } & \multirow[t]{2}{*}{1} & \multirow[t]{2}{*}{$\operatorname{RSC}(0.1 \mathrm{~g})$} & $\mathrm{Fe}$ & 0.0007 & 131.39 & 0.89 \\
\hline & & & $\mathrm{Mn}$ & 0.0011 & 203.58 & 0.9 \\
\hline & \multirow[t]{2}{*}{2} & \multirow[t]{2}{*}{ TLC (0.1 g) } & $\mathrm{Fe}$ & 0.0013 & 90.33 & 0.9 \\
\hline & & & $\mathrm{Mn}$ & 0.0010 & 70.40 & 0.98 \\
\hline & \multirow[t]{2}{*}{3} & \multirow[t]{2}{*}{ RSC (0.05 g) + NS (0.05 g) } & $\mathrm{Fe}$ & 0.0042 & 88.73 & 0.97 \\
\hline & & & $\mathrm{Mn}$ & 0.0013 & 235.45 & 0.91 \\
\hline & \multirow[t]{2}{*}{4} & \multirow[t]{2}{*}{$\mathrm{TLC}(0.05 \mathrm{~g})+\mathrm{NS}(0.05 \mathrm{~g})$} & $\mathrm{Fe}$ & 0.0037 & 65.71 & 0.88 \\
\hline & & & $\mathrm{Mn}$ & 0.0008 & 98.29 & 0.99 \\
\hline & \multirow[t]{2}{*}{5} & \multirow[t]{2}{*}{$\operatorname{RSC}(0.04 \mathrm{~g})+\mathrm{TLC}(0.04 \mathrm{~g})+\mathrm{NS}(0.02 \mathrm{~g})$} & $\mathrm{Fe}$ & 0.0008 & 112.75 & 0.83 \\
\hline & & & $\mathrm{Mn}$ & 0.0009 & 193.64 & 0.96 \\
\hline & \multirow[t]{2}{*}{6} & \multirow[t]{2}{*}{$\operatorname{RSC}(0.025 \mathrm{~g})+\mathrm{TLC}(0.025 \mathrm{~g})+\mathrm{NS}(0.05 \mathrm{~g})$} & $\mathrm{Fe}$ & 0.0005 & 158.63 & 0.91 \\
\hline & & & $\mathrm{Mn}$ & 0.0013 & 215.18 & 0.91 \\
\hline & \multirow[t]{2}{*}{7} & \multirow[t]{2}{*}{$\operatorname{RSC}(0.015 \mathrm{~g})+\mathrm{TLC}(0.015 \mathrm{~g})+\mathrm{NS}(0.07 \mathrm{~g})$} & $\mathrm{Fe}$ & 0.0007 & 222.56 & 0.85 \\
\hline & & & $\mathrm{Mn}$ & 0.0025 & 158.56 & 0.95 \\
\hline Model & $\begin{array}{l}\text { Sample } \\
\text { number }\end{array}$ & Adsorbent & Absorbed & $K_{\mathrm{BA}}(\mathrm{I} / \mathrm{mg} \mathrm{min})$ & $N_{0}(\mathrm{mg} / \mathrm{l})$ & $R^{2}$ \\
\hline \multirow[t]{14}{*}{ Adams-Bohart } & \multirow[t]{2}{*}{1} & \multirow[t]{2}{*}{$\operatorname{RSC}(0.1 \mathrm{~g})$} & $\mathrm{Fe}$ & 0.0005 & 5.85 & 0.95 \\
\hline & & & $\mathrm{Mn}$ & 0.0009 & 9.49 & 0.93 \\
\hline & \multirow[t]{2}{*}{2} & \multirow[t]{2}{*}{ TLC $(0.1 \mathrm{~g})$} & $\mathrm{Fe}$ & 0.0013 & 3.84 & 0.90 \\
\hline & & & $\mathrm{Mn}$ & 0.0010 & 2.99 & 0.98 \\
\hline & \multirow[t]{2}{*}{3} & \multirow[t]{2}{*}{ RSC (0.05 g) + NS (0.05 g) } & $\mathrm{Fe}$ & 0.0042 & 3.77 & 0.97 \\
\hline & & & $\mathrm{Mn}$ & 0.0021 & 7.35 & 0.89 \\
\hline & \multirow[t]{2}{*}{4} & \multirow[t]{2}{*}{$\mathrm{TLC}(0.05 \mathrm{~g})+\mathrm{NS}(0.05 \mathrm{~g})$} & $\mathrm{Fe}$ & 0.0008 & 3.53 & 0.88 \\
\hline & & & $\mathrm{Mn}$ & 0.0008 & 4.17 & 0.99 \\
\hline & \multirow[t]{2}{*}{5} & \multirow[t]{2}{*}{ RSC (0.04 g) + TLC (0.04 g) + NS (0.02 g) } & $\mathrm{Fe}$ & 0.0032 & 2.91 & 0.91 \\
\hline & & & $\mathrm{Mn}$ & 0.0009 & 8.22 & 0.96 \\
\hline & \multirow[t]{2}{*}{6} & \multirow{2}{*}{ RSC $(0.025 \mathrm{~g})+\mathrm{TLC}(0.025 \mathrm{~g})+\mathrm{NS}(0.05 \mathrm{~g})$} & $\mathrm{Fe}$ & 0.0005 & 6.74 & 0.91 \\
\hline & & & $\mathrm{Mn}$ & 0.0021 & 6.43 & 0.93 \\
\hline & \multirow[t]{2}{*}{7} & \multirow[t]{2}{*}{ RSC (0.015 g) + TLC (0.015 g) + NS (0.07 g) } & $\mathrm{Fe}$ & 0.0007 & 9.45 & 0.85 \\
\hline & & & $\mathrm{Mn}$ & 0.0028 & 6.41 & 0.94 \\
\hline
\end{tabular}

The results showed that the performance of NS with RSC is more efficient than other biosorbents combinations. In addition, Fe is absorbed more than Mn. The order of absorption of the systems is as follows: $(2)<(4)<(5)<(1)<(6)<(3)<(7)$, indicating that the adsorption performance improves with increasing the ratio of NS to other adsorbents

AA); then, the percentage of removed metal ions in solution is calculated using following equation:

$$
\% \text { Removal of metal ions }=\frac{C_{0-C_{t}}}{C_{0}} \times 100 \%
$$

Here, $\mathrm{C}_{0}(\mathrm{mg} / \mathrm{l})$ is the Initial concentration and $\mathrm{C}_{\mathrm{t}}$ $(\mathrm{mg} / \mathrm{l})$ is the final concentration of Fe and $\mathrm{Mn}$ ions in groundwater samples.

\section{Discussion}

As mentioned in the introduction, scientific research notes that biosorbents are very effective in removing undesirable elements from drinking water sources. The two main products in northern Iran are tea and rice.
After harvesting, they leave a lot of waste. Green tea leaf waste and rice straw were collected from farms and then processed. nanomaterials are attributed to the higher removal efficiency in adsorption. The use of biomaterials as a precursor for developing nanomaterials is a new research interest nowadays. The concept of green synthesis of nanosorbents from biological systems is environmentally friendly and stable. Present work aimed at developing a suitable nanomaterial-based adsorbent for the removal of low concentration of iron and manganese ions from Drinking water sources.

Various analyses (such as XRD, BET, SEM-EDX and FT-IR) were used to determine their characteristics. Due to XRD results (Fig. 2), the RSC has an amorphous 
Table 4 Physical characteristics of groundwater in Shaft city

\begin{tabular}{|c|c|c|c|c|c|c|c|c|}
\hline \multicolumn{7}{|l|}{ Inputs } & \multirow{2}{*}{\multicolumn{2}{|c|}{$\begin{array}{l}\text { Outputs } \\
\text { \% Removal of meta } \\
\text { ions }\end{array}$}} \\
\hline \multicolumn{5}{|c|}{ Effective parameters } & \multicolumn{2}{|c|}{ Initial concentration } & & \\
\hline Adsorbent & Temperature $\left({ }^{\circ} \mathrm{C}\right)$ & $\mathrm{pH}_{-}$ & Turbidity (NTU) & Color (pt-co) & $\mathrm{Fe}(\mathrm{mg} / \mathrm{l})$ & $\mathrm{Mn}(\mathrm{mg} / \mathrm{l})$ & $\mathrm{Fe}(\%)$ & $M n(\%)$ \\
\hline \multirow[t]{5}{*}{ TLC } & 24 & 7.97 & 1.1 & 38 & 0.57 & 0.73 & 88.60 & 67.26 \\
\hline & 20 & 7.81 & 1.51 & 20 & 0.75 & 1.39 & 86 & 75.18 \\
\hline & 20 & 7.42 & 3.50 & 21 & 0.73 & 1.07 & 86.99 & 78.13 \\
\hline & 20 & 7.22 & 5.51 & 20 & 1.26 & 0.88 & 83.97 & 72.27 \\
\hline & 20 & 7.79 & 1.45 & 22 & 0.66 & 1.49 & 85 & 78.05 \\
\hline \multirow[t]{5}{*}{ RSC } & 20 & 7.43 & 3.23 & 15 & 0.74 & 0.70 & 91.76 & 81.71 \\
\hline & 20 & 7.50 & 5.68 & 28 & 0.99 & 1.02 & 94.54 & 90.69 \\
\hline & 20 & 7.69 & 5.19 & 19 & 0.9 & 1.64 & 95.11 & 92.01 \\
\hline & 20 & 7.42 & 3.49 & 14 & 1.38 & 0.97 & 97.90 & 87.01 \\
\hline & 20 & 7.24 & 8.49 & 32 & 0.96 & 0.97 & 98.02 & 85.05 \\
\hline
\end{tabular}

The results showed that the proposed methods and adsorbents could be used with good efficiency for removal of undesirable elements from groundwater sources

structure, because there are no peaks that would show a symmetrical structure. According to the observation of peaks in TLC, it can be concluded that its structure is crystalline. In addition, the peaks conform to calcium carbonate with chemical formula of $\mathrm{Ca}$ (CO3). The surface morphology of nano-biosorbents after adsorption is shown in Figs. 3, 4 and 5, respectively. Based on SEM analysis, the abundant porous and irregular structure of the nano-biosorbents could enable the easy access of $\mathrm{Fe}$ and $\mathrm{Mn}$ ions into it. In addition, in the sample sent to the laboratory for EDX analysis, only the amount of iron and manganese in the sample was given in the results. It should be noted that the raw sample of the adsorbent contains Silica, carbon and oxygen. In the final sample, the highest amount of ions was related to iron and manganese and other elements were ignored. BET and $\mathrm{BJH}$ analysis (Table 1) was used to measure the specific surface area and pore size of the adsorbents. With converting ordinary biosorbent (TL and RS) to char (TLC and RSC) and based on BET analysis, the specific surface area $\left(\mathrm{m}^{2} / \mathrm{g}\right)$ of tea leaves increased from 0.29 (TL) to 3.45 (TLC); and rice straw increased from 3.70 (RS) to 10.99 (RSC) as well. The results of FTIR analysis (Figs. 6 and 7) pinpoint to the strong interaction between functional groups and adsorbate. The results of the analysis of adsorbents showed that they can be used to reduce undesirable elements such as iron and manganese from drinking water sources.

The column operation provides more proficient utilization of the adsorbent's capacity compared to the batch process. Due to the high rate of drinking water consumption, continuous methods should be used to purify drinking water resources.
In the present study, nano-biosorbents include TLC, RSC and NS are packed in the column, and iron with manganese solution of initial concentration $5 \mathrm{mg} / \mathrm{l}$ is passed through it. A polyester membrane filter was used to hold the adsorbent. According to the pre-tests performed, the amount of adsorbent was considered $0.1 \mathrm{~g}$. If the amount of adsorbent used is high, the saturation time of the adsorption column will be very long. The maximum height of the adsorbent in the adsorption column was $2 \mathrm{~cm}$ and the solution containing iron and manganese entered from the top of the adsorption column and left the end of the column after contact with the adsorbent. To keep the solution in the upper part of the adsorbent, the height of the adsorption column was considered to be $50 \mathrm{~cm}$. The flow rate was maintained at $10 \mathrm{ml} / \mathrm{min}$, and the $\mathrm{pH}$ of the stock solution was 7.9. A flowmeter was used to show the flow rate. Several control valves were used to control and regulate the flow in the process path. The flow was transferred from the source to the top of the column by a pump. A reciprocating flow was also used in the flow path after the pump. The process temperature was controlled by a heat source installed in the system. Both the source and the absorption column had a heat source. A heating element was used inside the source and its temperature was controlled using a thermostat. A filament heating element was used to control the temperature of the column. The element was immersed in water. The temperature of the element was controlled using a thermostat. The temperature was $30{ }^{\circ} \mathrm{C}$. This was achieved due to the many pre-tests that were performed.

The composition percentage of nano-biosorbents is one of the critical parameters in evaluating the adsorption 
performance of sorbent in continuous column studies. The experiments on seven different nano-biosorbents were conducted to evaluate the effect of composition percentage of nano-biosorbents for continuous removal of Fe and $\mathrm{Mn}$ ions in the packed bed adsorption column. The composition percentage applied were 1: RSC $(0.1 \mathrm{~g}), 2$ : TLC (0.1 g), 3: RSC (0.05 g) + NS (0.05 g), 4: TLC (0.05 g) + NS $(0.05 \mathrm{~g}), 5$ : RSC $(0.04 \mathrm{~g})+\mathrm{TLC}(0.04 \mathrm{~g})+\mathrm{NS}(0.02 \mathrm{~g}), 6$ : RSC $(0.025 \mathrm{~g})+\mathrm{TLC}(0.025 \mathrm{~g})+\mathrm{NS}(0.05 \mathrm{~g})$ and 7 : RSC $(0.015 \mathrm{~g})+$ TLC $(0.015 \mathrm{~g})+\mathrm{NS}(0.07 \mathrm{~g})$ to determine the breakthrough of the Fe and Mn solution. When nanobiosorbents composition percentage changes, consequently, there will be a change in removal percent of $\mathrm{Fe}$ and $\mathrm{Mn}$ ions in the column. Figures 8 and 9 represent the breakthrough curves at different composition percentage of nano-biosorbents. The plot clearly shows that the amount of $\mathrm{Fe}$ and $\mathrm{Mn}$ ions adsorbed increased with an increase in NS. The slightly different shape and gradient of the breakthrough curve could be seen with the variation of composition percentage of nano-biosorbents. As the NS of the column was increased, the breakthrough curve shifted from left to right. The breakthrough occurred slowly for the Sample number 7 than for 3, 6, 1, 5, 4 and Sample number 2. The increase in Fe and $\mathrm{Mn}$ ions uptake capacities with higher NS in the column is due to the increase in specific surface area of the adsorbent. Therefore, more Fe and $\mathrm{Mn}$ ions can be fixed on the active sites of the nanobiosorbents film. The exhaustion time of adsorbent was increased for higher NS. The delayed exhaustion time shows that the bed is able to operate for a longer period without changing the nano-biosorbents packing. The higher Fe and Mn ions sorption capacity at higher NS can also be attributed to the sufficient residence time of the cation in the adsorption column. This provides ample time for diffusion or interaction of the $\mathrm{Fe}$ and $\mathrm{Mn}$ ions with nano-biosorbents films. The total removal percentage of Fe and Mn column was seen to increase with NS (Table 2). For Sample number 7 and 2, $q_{\mathrm{eq}}(\mathrm{mg} / \mathrm{g})$ of Fe and $\mathrm{Mn}$ ions were 256.56, 244.79, 130.03 and 110.08 , respectively. In addition, the total removal percentage of $\mathrm{Fe}$ and $\mathrm{Mn}$ ions $(\% R)$ were obtained as $98.05,97.92,72.24$ and $52.56 \%$, respectively. A drastic increase in the breakthrough was seen in the first part of the column operation at a Sample number 7 . The contact period between the Fe and Mn solution and the adsorbent bed was short at a Sample number 2. From the continuous study of Fe and Mn removal in the fixed bed adsorption column with nanobiosorbents films, it is found that that Sample number 7 is favourable for treating higher volume of the aqueous solution. Slower breakthrough and longer residence time of $\mathrm{Fe}$ and $\mathrm{Mn}$ ions in the bed could be achieved at lower TLC and higher NS. Therefore, the results inferred that RSC and NS significantly influenced both column breakthrough time and the nanofilm bed performance. The data obtained from the column adsorption experiment were applied into mathematical theories to get information on the influencing parameters. This gives us a more comprehensive, complete and clear view of the effect of independent variables in the absorption process.

The correlation between experimental and theoretical data of column operation was compared with two models (Table 3). Correlation coefficients for samples 1 to 7 for Thomas and Adams-Bohart model are above 0.83. The calculated $R^{2}$ values for the experimental conditions Sample number 7 and 2 shows close agreement $\left(R^{2}=0.95\right.$ and 0.98 for Thomas model and $R^{2}=0.94$ and 0.98 for Adams-Bohart model). From the values of the correlation coefficient, the Thomas model was found to fit well to the experimental data. Adam Bohart correlation was proved best for the initial part of the adsorption process.

Also in this research, real samples were collected from groundwater and their iron and manganese levels were measured using an atomic absorption device. Then, the samples were placed in the vicinity of plant adsorbents (TLC and RSC) using a fixed bed column, and the amount of iron and manganese in the final samples was measured again, and the results indicate the good performance of the adsorbents.

Overall, the experimental results, breakthrough curves, and Thomas and Adams-Bohart models showed that the adsorption capacity of RSC is greater than that of TLC, and RSC with NS absorbs more Fe than Mn.

\section{Conclusions}

The results of the present study proved the ability of RSC, TLC, and NS in removing Fe and Mn ions. The XRD, FTIR, SEM-EDX, and BET analyses were applied to characterize the used adsorbents. The experimental results revealed that the char made of tea leaves and rice straw with nanosilica were applicable to remove $\mathrm{Fe}$ and $\mathrm{Mn}$ ions from groundwater. The higher percentages of nanosilica resulted in higher absorption of iron and manganese from the aqueous solution. Thomas and Adams-Bohart models sufficiently explained the adsorption of $\mathrm{Fe}$ and $\mathrm{Mn}$ ions onto nanobiosorbents in the column mode. The constants for Thomas and Adams-Bohart mathematical models were calculated. The $q_{0}$ values of iron and manganese ions removal by the best combination of TLC, RSC, and NS (the seventh mode) were 222.56 and $158.56 \mathrm{mg} / \mathrm{g}$, respectively. Meanwhile, the corresponding $N_{0}$ values were 9.45 and $6.41 \mathrm{mg} / \mathrm{l}$, respectively. In real systems, biosorbents can be used with good efficiency to remove undesirable elements from groundwater sources. The results indicated that the impact of rice straw char was more significant than tea leaves char, and nano-biosorbents had more iron than manganese ions. 


\section{Abbreviations}

RSC: Rice straw-derived char; TLC: Tea leaves-derived char; NS: Nanosilica; Fe: Iron; Mn: Manganese; XRD: X-ray diffractometer; FTIR: Fourier transforms infrared spectra; SEM: Scanning electron microscopy; EDX: Energy dispersive X-ray; BET: Brunauer-Emmett-Teller; BJH: Barrett-Joyner-Halenda.

\section{Acknowledgements}

The authors sincerely thank the laboratory unit of the Faculty of Engineering of the University of Guilan for supporting this research.

\section{Authors' contributions}

$A D$ and BAS conceived and designed the experimental strategies and manuscript. MAZ performed all experiments and data analysis. BAS and AD provided valuable understandings to improve experimental strategy. MAZ has written the original draft of manuscript. AD and BAS have revised and validated the results. All authors read and approved the final manuscript.

\section{Funding}

The authors acknowledge university of guilan for the financial support.

\section{Availability of data and materials}

The data set used and/or analyzed during the current study are available from the corresponding author on reasonable request.

\section{Declarations}

\section{Ethics approval and consent to participate}

This manuscript is an original research and has not been published in other journals.

\section{Consent for publication}

All authors agreed to publish in the journal.

\section{Competing interests}

The authors declare that they have no competing interests.

Received: 3 June 2021 Accepted: 21 October 2021

Published online: 13 January 2022

\section{References}

1. Jusoh AB, Cheng W, Low W, Nor'aaini A, Noor MMM. Study on the removal of iron and manganese in groundwater by granular activated carbon. Desalination. 2005;182(1-3):347-53.

2. Nassar MM, Awida KT, Ebrahiem EE, Magdy YH, Mehaedi MH. Fixed-bed adsorption for the removal of iron and manganese onto palm fruit bunch and maize cob. Adsorpt Sci Technol. 2003;21(2):161-75.

3. Akoto $\mathrm{O}$, Adiyiah J. Chemical analysis of drinking water from some communities in the Brong Ahafo region. Int J Environ Sci Technol. 2007:4(2):211-4.

4. Maliki S, Rosnelly C, Adisalamun A, Husin H, Bilqis N. Removal of Fe (li) in groundwater using rice husk-sourced biosorbent in continuous column adsorption. J Phys Conf Ser. 2019;1402:055007.

5. Patel $\mathrm{H}$. Fixed-bed column adsorption study: a comprehensive review. Appl Water Sci. 2019;9(3):45.

6. Jain CK, Malik DS, Yadav AK. Applicability of plant based biosorbents in the removal of heavy metals: a review. Environ Process. 2016;3(2):495-523.

7. Hussain S, Anjali K, Hassan ST, Dwivedi PB. Waste tea as a novel adsorbent: a review. Appl Water Sci. 2018;8(6):1-16.

8. Suwunwong T, Danwittayakul $\mathrm{P}$, Thanomsilp C, Siriwat $\mathrm{P}$, Chantrapromma $\mathrm{S}$, Phoungthong K. The removal of $\mathrm{Pb} 2+$ ion by MnFe2O4/waste tea leaves biochar and mechanism of adsorption. Mater Res Express. 2021;8(1):015505

9. Adekola F, Hodonou D, Adegoke H. Thermodynamic and kinetic studies of biosorption of iron and manganese from aqueous medium using rice husk ash. Appl Water Sci. 2016:6(4):319-30.

10. Goher ME, Hassan AM, Abdel-Moniem IA, Fahmy AH, Abdo MH, El-sayed SM. Removal of aluminum, iron and manganese ions from industrial wastes using granular activated carbon and Amberlite IR-120H. Egypt J Aquat Res. 2015;41(2):155-64.

11. Tuli F, Hossain A, Kibria AF, Tareq A, Mamun SM, Ullah AA. Removal of methylene blue from water by low-cost activated carbon prepared from tea waste: astudy of adsorption isotherm and kinetics. Environ Nanotechnol Monit Manag. 2020;14:100354.

12. Hameed B, El-Khaiary M. Kinetics and equilibrium studies of malachite green adsorption on rice straw-derived char. J Hazard Mater. 2008;153(1-2):701-8

13. Nguyen TH, Pham TH, Nguyen Thi HT, Nguyen TN, Nguyen MV, Tran Dinh T, Nguyen MP, Do TQ, Phuong T, Hoang TT. Synthesis of iron-modified biochar derived from rice straw and its application to arsenic removal. J Chem. 2019;2019:1-8.

14. Zhang Y, Yue $X, X u$ W, Zhang H, Li F. Amino modification of rice strawderived biochar for enhancing its cadmium (II) ions adsorption from water. J Hazard Mater. 2019:379:120783.

15. Salimi F, Tahmasobi K, Karami C, Jahangiri A. Preparation of modified nano- $\mathrm{SiO}_{2}$ by bismuth and iron as a novel remover of methylene blue from water solution. J Mex Chem Soc. 2017;61(3):250-9.

16. Chen N, Zhang Z, Feng C, Li M, Chen R, Sugiura N. Investigations on the batch and fixed-bed column performance of fluoride adsorption by Kanuma mud. Desalination. 2011;268(1-3):76-82.

17. Jain SN, Tamboli SR, Sutar DS, Jadhav SR, Marathe JV, Shaikh AA, Prajapati AA. Batch and continuous studies for adsorption of anionic dye onto waste tea residue: kinetic, equilibrium, breakthrough and reusability studies. J Clean Prod. 2020;252:119778.

18. Mpouras T, Polydera A, Dermatas D, Verdone N, Vilardi G. Multi wall carbon nanotubes application for treatment of $\mathrm{Cr}(\mathrm{VI})$-contaminated groundwater; modeling of batch \& column experiments. Chemosphere. 2021;269:128749

19. Agarwal MR, Singh K, Gupta R, Dohare R. Continuous fixed-bed adsorption of heavy metals using biodegradable adsorbent: modeling and experimental study. J Environ Eng. 2020;146(2):04019110.

20. Amarasinghe $B$, Williams RA. Tea waste as a low cost adsorbent for the removal of $\mathrm{Cu}$ and $\mathrm{Pb}$ from wastewater. Chem Eng J. 2007;132(1-3):299-309.

21. Fu P, Hu S, Xiang J, Sun L, Su S, Wang J. Evaluation of the porous structure development of chars from pyrolysis of rice straw: effects of pyrolysis temperature and heating rate. J Anal Appl Pyrolysis. 2012;98:177-83.

22. Vilardi G, Bubbico R, Di Palma L, Verdone N. Nitrate green removal by fixed-bed columns packed with waste biomass: modelling and friction parameter estimation. Chem Eng Res Des. 2020;154:250-61.

23. Asemave K, Thaddeus L, Tarhemba PT. Lignocellulosic-based sorbents: a review. Sustain Chem. 2021;2(2):271-85

24. Wang JY, Cui H, Cui CW, Xing DF. Biosorption of copper (II) from aqueous solutions by Aspergillus niger-treated rice straw. Ecol Eng. 2016:95:793-9.

25. Rusdianasari R, Taufik M, Bow Y, Fitria MS. Application of nanosilica from rice husk ash as iron metal (Fe) adsorbent in textile wastewater. Indones Fundamental Appl Chem. 2020;5(1):7-12.

26. Manyangadze M, Chikuruwo NM, Narsaiah TB, Chakra CS, Charis G, Danha $G$, Mamvura TA. Adsorption of lead ions from wastewater using nano silica spheres synthesized on calcium carbonate templates. Heliyon. 2020;6(11):e05309.

27. Yang J, Hou B, Wang J, Tian B, Bi J, Wang N, Li X, Huang X. Nanomaterials for the removal of heavy metals from wastewater. Nanomaterials. 2019;9(3):424.

28. Tan G, Wu Y, Liu Y, Xiao D. Removal of Pb (II) ions from aqueous solution by manganese oxide coated rice straw biochar A low-cost and highly effective sorbent. J Taiwan Inst Chem Engrs. 2018;84:85-92.

29. Zhang YI Wu, Wg ZS, Yf L, Luo Yh. Experimental study on pyrolysis tar removal over rice straw char and inner pore structure evolution of char. Fuel Process Technol. 2015;134:333-44.

30. Mondal $\mathrm{M}$. Removal of $\mathrm{Pb}$ (II) ions from aqueous solution using activated tea waste: adsorption on a fixed-bed column. J Environ Manage. 2009;90(11):3266-71.

31. Armynah B, Djafar Z, Piarah WH, Tahir D. Analysis of chemical and physical properties of biochar from rice husk biomass. J Phys Conf Ser. 2018;979:012038.

32. Bhoyate S, Ranaweera CK, Zhang C, Morey T, Hyatt M, Kahol PK, Ghimire M, Mishra SR, Gupta RK. Eco-friendly and high performance 
supercapacitors for elevated temperature applications using recycled tea leaves. Glob Chall. 2017;1 (8):1700063.

33. Ramesh P, Saravanan K, Manogar P, Johnson J, Vinoth E, Mayakannan $M$. Green synthesis and characterization of biocompatible zinc oxide nanoparticles and evaluation of its antibacterial potential. Sens Bio Sens Res. 2021;31:100399.

34. Xu F, Zhu TT, Rao QQ, Shui SW, Li WW, He HB, Yao RS. Fabrication of mesoporous lignin-based biosorbent from rice straw and its application for heavy-metal-ion removal. Res J Environ Sci. 2017:53:132-40.

35. Zhou J, Luo A, Zhao Y. Preparation and characterisation of activated carbon from waste tea by physical activation using steam. J Air Waste Manag Assoc. 2018;68(12):1269-77.

36. Manjunath S, Kumar M. Simultaneous removal of antibiotic and nutrients via Prosopis juliflora activated carbon column: performance evaluation, effect of operational parameters and breakthrough modeling. Chemosphere. 2021;262:127820

37. Malkoc E, Nuhoglu Y. Removal of $\mathrm{Ni}$ (II) ions from aqueous solutions using waste of tea factory: adsorption on a fixed-bed column. J Hazard Mater. 2006;135(1-3):328-36.

38. Faizal AM, Kutty SRM, Ezechi EH. Modelling of Adams-Bohart and YoonNelson on the removal of oil from water using microwave incinerated rice husk ash (MIRHA). Appl Mech Mater. 2014;625:788.

\section{Publisher's Note}

Springer Nature remains neutral with regard to jurisdictional claims in published maps and institutional affiliations.

\section{Submit your manuscript to a SpringerOpen ${ }^{\circ}$ journal and benefit from:}

- Convenient online submission

- Rigorous peer review

- Open access: articles freely available online

- High visibility within the field

- Retaining the copyright to your article

Submit your next manuscript at $\boldsymbol{\nabla}$ springeropen.com 